\title{
PROCESSO DE INCLUSÃO DE ESTUDANTES SURDOS: NOVAS PERSPECTIVAS E POSSIBILIDADES
}

\author{
Michele da Rosa Scholant Simões ${ }^{1}$
}

\begin{abstract}
RESUMO: Introdução: Este artigo focaliza uma experiência de inclusão de aluno surdo em escola regular, com a presença de intérprete de língua de sinais. Apresentando os problemas que ocorrem no espaço escolar, sobre a surdez e sobre suas implicações educacionais, dificuldades com adaptações curriculares e estratégias de aula, exclusão do aluno surdo de atividades. Objetivo: Pretende-se contribuir para a reflexão acerca de práticas inclusivas envolvendo surdos, procurando compreender seus efeitos, limites e possibilidades e buscando uma atitude educacional responsável. Metodologia: Trata- se de uma revisão e literatura, com embasamento em materiais publicados sobre o assunto: livros, artigos científicos, publicações periódicas e materiais disponíveis na internet nos seguintes bancos de dados: dados PUBMED, MEDLINE e SCIELO abordando os escritores relacionados ao tema. Conclusão: Conclui-se que a inclusão de surdos no ensino regular significa mais do que apenas criar vagas e proporcionar recursos materiais, é necessário que a escola e a sociedade sejam inclusivas, assegurando igualdade de oportunidades a todos os alunos e contando com professores capacitados e compromissados com a educação de todos.
\end{abstract}

Palavras-chave: Inclusão escolar. Surdez. Intérprete de Língua Brasileira de Sinais.

ABSTRACT: Introduction: This article focuses on an experience of inclusion of deaf students in regular schools, with the presence of a sign language interpreter. Presenting the problems that occur in the school environment, about deafness and its educational implications, difficulties with curricular adaptations and classroom strategies, exclusion of deaf students from activities. Objective: It is intended to contribute to the reflection on inclusive practices involving deaf people, seeking to understand their effects, limits and possibilities and seeking a responsible educational attitude. Methodology: This is a literature review, based on published materials on the subject: books, scientific articles, periodicals and materials available on the internet in the following databases: PUBMED, MEDLINE and SCIELO data addressing writers related to the topic . Conclusion: It is concluded that the inclusion of deaf people in regular education means more than just creating places and providing material resources, it is necessary that the school and society be inclusive, ensuring equal opportunities for all students and relying on trained teachers and committed to the education of all.

Keywords: School inclusion. Deafness. Brazilian Sign Language Interpreter.

\footnotetext{
${ }^{1}$ Médica veterinária. Doutora em melhoramento genético pela UFPEL.
} 


\section{I- INTRODUÇÃO}

Considera-se pessoa surda aquela que tem a compreensão do mundo por meio de experiências visuais, tendo uma cultura e língua - a Língua Brasileira de Sinais (LIBRAS), no caso do Brasil. Os surdos, vistos na perspectiva cultural, fazem parte de uma comunidade (a comunidade surda), apresentando identidade e língua próprias. A educação inclusiva procura atender às necessidades dos estudantes surdos, garantindo a sua participação nas diversas situações de aprendizagem, dentro e fora da sala de aula.

De acordo com Sanches e Teodoro (2007), numa escola inclusiva só pode existir uma educação inclusiva, uma educação em que a heterogeneidade do grupo não é mais um problema, mas um grande desafio à criatividade e ao profissionalismo dos profissionais da Educação (p. IIo). Enquanto professores, deparamo-nos com as salas de aulas repletas de pessoas, cada uma com a sua identidade, costumes, cultura, religião, vida própria, um autêntico "arco-íris" (Sanches, 20Irb). A diversidade de experiências, de saberes e de culturas dos alunos é uma mais-valia geradora de novos conhecimentos, campo aberto para experienciar diferentes metodologias em que as aprendizagens sejam construídas com a mediação do professor, do grupo escolar e da família, valorizando as experiências e potencialidades de cada um.

O presente artigo dá conta de um estudo que procura compreender o processo de inclusão dos estudantes surdos, através das suas percepções. Parte do pressuposto de que a educação inclusiva se preocupa em promover a participação dos estudantes e procura reduzir a exclusão, reestruturando culturas, políticas e práticas pedagógicas, nas instituições de ensino, respondendo continuamente à diversidade dos estudantes.

Desse modo, várias têm sido as maneiras de realização da inclusão. Contudo, é inegável que a maioria dos estudantes surdos sofreu uma escolarização pouco responsável. Este trabalho tem como finalidade compreender a importância e necessidade da educação inclusiva voltada para os desafios das crianças surdas no processo de alfabetização. objetivou-se apresentar desafios das crianças surdas no processo de alfabetização, e refletir sobre o desafio dos docentes e do contexto do sistema escolar perante a aprendizagem de alunos surdos.

Neste estudo abordamos especificamente a educação inclusiva em contexto escolar, ressaltando a importância da Língua Brasileira de Sinais - LIBRAS. Após o 
enquadramento teórico, apresentamos os procedimentos metodológicos e, por fim, a análise e discussão dos resultados. Concluímos com algumas considerações finais.

\section{CAPÍTULO}

\section{I Reflexões da Inclusão no Contexto Escolar}

Definir educação através dos escritos citados, de uma forma global nos orientar a base educacional para todos, a inclusão hoje é um ponto de partida para a igualdade social a nível de educação, pois há várias maneiras de aprender cada um no seu ritmo, a inclusão de alunos com diferentes necessidades requer uma certa organização a nível curricular, trabalhos diversificados que possa garantir um bom nível de aprendizagem para todos. É preciso um esforço maior por parte dos educadores junto as comunidades para ampliar os horizontes educacionais nas escolas.

O princípio fundamental das escolas inclusivas consiste em todos os alunos aprenderem juntos, sempre que possível, independentemente das dificuldades e das diferenças que apresentem. Estas escolas devem reconhecer e satisfazer as necessidades diversas dos seus alunos, adaptando-se aos vários estilos e ritmos de aprendizagem, de modo a garantir um bom nível de educação para todos, através de currículos adequados, de uma boa organização escolar, de estratégias pedagógicas, de utilização de recursos e de uma cooperação com as respectivas comunidades. É preciso, portanto, um conjunto de apoios e de serviços para satisfazer o conjunto de necessidades especiais dentro da escola. (Declaração de Salamanca, I994, p. II-12).

Toda criança tem direito à educação, independentes de suas diferenças, toda criança possui características, habilidades e necessidades de aprendizagem que são únicas. O sistema educacional deveria ser designado com programas educacionais implementados no sentido de adaptar as diversidades de todos. Toda criança com necessidades especiais tem o direito o acesso à escola regular como um todo, a escola tem por obrigação acomodá-los de maneira igualitária com uma pedagogia inovadora que permita a inclusão sem exclusão, construindo uma sociedade inclusiva que alcança a todos de modo acolhedor.

A inclusão escolar é um grande avanço sobre a igualdade social, refletirmos de modo igualitário o grande avanço das escolas tradicionais sofreram ao longo do tempo. Nos últimos anos a inclusão social colaborou para a criação de políticas e leis de programas e serviços voltados ao atendimento de indivíduos com necessidades educacionais especiais, designando novas condições de adequações as pessoas que são 
excluídos. O Brasil alcançou um progresso formidável no processo de educação inclusiva com a invenção da Lei de Diretrizes e Bases da Educação Nacional 9394/96, que em garante a todos os mesmos direitos (JÚNIOR, 2012).

A inclusão constitui que a sociedade deve acomodar-se às precisões da pessoa com deficiência para que esta consiga desenvolver-se os aspectos de sua vida a luta pela inclusão das pessoas com deficiência é apoiada no mundo todo, indo embora para trás a a discriminação e o descaso de anos atrás em relação às suas precisões individualizadas. (SASSAKI, 1997, p. 167).

A partir de 1990 teve as primeiras preocupações entre profissionais, familiares, pesquisadores e governos para que tivesse a inclusão de estudantes com necessidades educacionais especiais nas redes de ensino regular. Quando discorremos dentro do termo necessidades educacionais especiais aludimos a vivência de um empecilho na aprendizagem, advertindo que os estudantes com necessidades carecem de recursos e serviços educacionais distintos dentro do ambiente escolar, o que faz com que os sistemas de ensino e, especialmente os docentes, procurem caminhos novos para proporcionar recursos e serviços apropriados para cada educando (SASSAKI, 1997, p. 167).

Educação inclusiva é o processo que ocorre em escolas de qualquer nível preparadas para propiciar um ensino de qualidade a todos os alunos independentemente de seus atributos pessoais, inteligências, estilos de aprendizagem e necessidades comuns ou especiais. A inclusão escolar é uma forma de inserção em que a escola comum tradicional é modificada para ser capaz de acolher qualquer aluno incondicionalmente e de propiciar-lhe uma educação de qualidade. $\mathrm{Na}$ inclusão, as pessoas com deficiência estudam na escola que frequentariam se não fossem deficientes. (SASSAKI, 1998, p. 8).

É importante ressaltar que antes da inclusão vivenciamos um momento de exclusão das pessoas com necessidades especiais, trazendo em sim malefícios para a educação igualitária para todos. Até hoje muitas escolas não estão fisicamente adaptadas para receber uma criança com uma deficiência que requer o uso de uma cadeira de rodas por exemplo, seja pela falta de rampa de acesso ou elevadores que possibilite esse aluno adentrar na escola, logo observamos uma exclusão por parte do ambiente escolar. 
Temos que entender que estamos no mundo pós-moderno na era da inclusão que é um direito adquirido por lei para todos.

\subsection{O processo de inclusão de estudantes surdos: Reflexões da prática docente}

Sendo a educação especial um campo de pesquisa inovadora da pedagogia, diversos docentes buscam teorias e práticas focadas ao ensino de qualidade, com profissionais comprometidos em dar aos seus estudantes um ensino de qualidade, independentemente de suas diferenças individuais. $O$ ideal é que na experiência educativa, estudantes, e educadores, ligados possam conviver de tal forma para o aprimoramento educacional. (FREIRE, 2005, p. 58)

Recentemente, para erguer uma escola que receba de forma adequada a estudantes com qualidades e potenciais diferentes de aprendizagem, não basta tãosomente que tenham docentes e demais profissionais que uma escola normal oferece. Faz-se imprescindível que os profissionais e sobretudo os professores permaneçam habilitados para desempenhar essa função, acolhendo a precisão de cada estudante.

A formação de docentes para operar na educação básica far-se-á em nível superior, em curso de licenciatura, de graduação plena, em universidades e institutos superiores de educação, admitida, como formação mínima para o exercício do magistério na educação infantil e nas quatro primeiras séries do ensino fundamental (BRASIL, 1998)

Diante de tais precisões especiais educacionais, o papel do docente é de total importância na educação inclusiva, competente, guiar a metodologia pedagógico de ensino, sendo o mediador entre o aluno e o conhecimento e cabe a ele promover circunstâncias pedagógicas em que os estudantes com necessidades educacionais especiais superem o senso comum quebrando as barreiras que se impõem. Os docentes necessitam refletir na educação como um todo, segundo Farfus (2008).

Garantir a inclusão e garantir o futuro das pessoas que buscam na educação uma qualidade de vida melhor, que possa quebrar barreiras que impedem o acesso igualitária para todos. Trabalhar a inclusão de forma justa garantido o acesso que por lei foram garantidos principalmente no que diz respeitos ao currículo pedagógico que possa agregar valores e qualidades na distribuição educacional. A importância da inclusão e 
vista de forma nítida nos dias atuais trazendo uma igualdade justa para todos. Dessa forma a inclusão é importante para poder viabilizar o processo de democratização educacional .

\begin{abstract}
O que se pretende na educação inclusiva é remover barreiras, sejam elas extrínsecas ou intrínsecas aos alunos, buscando-se todas as formas de acessibilidade e de apoio de modo a assegurar (o que a lei faz) e, principalmente garantir (o que deve constar dos projetos político pedagógicos dos sistemas de ensino e das escolas e que deve ser executado), tomando-se as providências para efetivar ações para o acesso, ingresso e permanência bemsucedida na escola (CARVALHO, 2005, p.72).
\end{abstract}

Diante do exposto citado buscamos uma melhora na base educacional quebrando barreiras sociais que impedem o acesso a lugares remotos que hoje são uma barreira para as pessoas que compõe necessidades especiais. Direitos garantidos por lei a toda criança que apresente algum tipo de necessidade especial tenha o livre acesso a desenvolver suas capacidades e habilidades em ambientes e aprimorar suas habilidades emocionais por meio da inclusão escolar. As barreiras encontradas hoje ainda é um fator predominante na maioria dos lugares fazendo com que as pessoas se sintam menos importante na sociedade em que vive.

As barreiras encontradas no dia a dia têm sido grandes constrangimentos pessoais para a inclusão educacional, que é, tentar corrigir a exclusão de alguns grupos, como cadeirante, autista entre outros. Trabalhar essa diversidade desde os primórdios da vida, trará sem dúvidas benefícios para a vida social trazendo a compreensão dos direitos adquiridos ao longo do tempo, o trabalho comunitário de inclusão é um grande aliado para essa melhoria na vivência das pessoas. A escola em sim é o ponto inicial para essa política de aceitabilidade de todos.

A inclusão de alunos com necessidades educacionais especiais na rede regular
de ensino não se restringe aos esforços da escola, inclui também a construção
de redes de colaboração com a família e a sociedade fortalecendo o combate à
intolerância e às barreiras atitudinais, bem como a compreensão da
diversidade no desenvolvimento infantil (ARRUDA; ALMEIDA, 2004, p. 16).

É notório analisar de forma a garantir os benefícios que a inclusão pode agregar na vida da comunidade, hoje pode se dizer que a escola muitas vezes se restringi a essa informação, passando muitas vezes de forma imparcial para as comunidades, que deveria ser uma grande aliada ao combate à exclusão social. A diversidade de exclusão ainda é tabu para a sociedade em pleno século XXI, ainda nos deparamos com a 
discriminação de pessoa que são diferenciadas por seu modo físicos sociais ou até mesmo seus modos de vida que é visto como diferente dos demais da sociedade.

É muito comum os profissionais nas escolas se referirem aos alunos com alguma necessidade especial, como o aluno de inclusão ou o aluno especial. Essa inclusão a qual o autor se refere nos molda de forma aceitável. As escolas tentam inserir todos esses alunos com necessidades especiais no ensino regular, buscando assim uma educação para todos.

\footnotetext{
Por outro lado, a inclusão busca inserir todos os alunos no ensino regular, não havendo exceção para este ou aquele aluno. "As escolas inclusivas propõem um modo de organização do sistema educacional que considera as necessidades de todos os alunos e que é estruturado em função dessas necessidades." (MANTOAN, 2003, p. 24).
}

Conforme o autor citou, a inclusão busca inserir todos os alunos, mas quando começamos a falar de educação inclusiva, desse processo de inclusão dessa criança no ensino regular, a primeira instância a gente precisa entender que a educação ela é um direito constitucional, um direito para todos, independentemente de sua classe social, raça ou religião, é importante que isso é direito garantido pela nossa constituição. Mesmo sabendo que essa criança tem o direito de estar na sala de aula, ainda sim, existe a exclusão desse aluno. Não falo só da falta de escolas adaptadas, mas de profissionais capacitados também, isso é uma realidade que eles enfrentam.

\subsection{Conceituando a Surdez: Causas, características}

Definir o surdo como uma pessoa que apreende com o mundo por meio de contatos visuais, não é uma tarefa fácil, pois vimos que cada autor define de várias maneiras. Uns vão definir como uma característica especial de um grupo, e não como uma deficiência. Outros define como aquele que não fala, só utiliza a língua de sinais LIBRAS, capaz de falar e de ser oralizado.

Já Campos (2014, p. 48) define o surdo como: aquele que apreende o mundo por meio de contatos visuais, que é capaz de se apropriar da língua de sinais e da língua escrita e de outras, de modo a propiciar seu pleno desenvolvimento cognitivo, cultural e social.

O surdo é aquela pessoa que se aceita enquanto surdo, ele tem uma cultura surda e participa da comunidade surda, e se utiliza da língua de sinais que é o principal. Um deficiente auditivo, ele não se aceita enquanto surdo, ele não tem uma identidade 
surda, ele não participa da comunidade surda, muitas vezes ele se utiliza de implantes de aparelho auditivo e também da oralidade.

O decreto de $\mathrm{n}^{\mathrm{o}} 5.626$, de 22 de janeiro de 2005, foi publicado para regulamentar duas leis publicadas anteriormente. A lei de no 10.436 de 2002, e o artigo 18 da lei ro.098 de 2000. A lei de ro.436 é a lei que reconheceu a LIBRAS como língua no Brasil, pois antes a língua de sinais não era considerada uma língua em nosso país, e sim um tipo de linguagem que se utilizava de sinais.

Isso é muito claro para todos, que até pouco tempo atrás a LIBRAS era vista como uma linguagem e não como uma língua. A outra lei de 10.098 no ano de 200o, que trata da acessibilidade no seu artigo 18 , diz que o poder público implementaria a formação de profissionais intérprete e de guias interprete, não dizendo como isso iria acontecer e nem demandando assim uma nova lei para estabelecer como essa formação ocorreria

O Decreto no 5.626, de 22 de janeiro de 2005, regulamenta a Lei no 10.436 , de 24 de abril de 2002, e o art. I8 da Lei no ro.098, de i9 de dezembro de 2000. Segundo ele: Considera-se pessoa surda aquela que, por ter perda auditiva, compreende e interage com o mundo por meio de experiências visuais, manifestando sua cultura principalmente pelo uso da Libras. - considera-se deficiência auditiva a perda bilateral, parcial ou total, de $4 \mathrm{I}$ decibéis $(\mathrm{dB})$ ou mais, aferida por audiograma nas frequências de $500 \mathrm{~Hz}, 1.000 \mathrm{~Hz}$, 2.00o $\mathrm{Hz}$ e 3.00o Hz.

É importante entender que nesse contexto, uma pessoa que apresenta perda auditiva, mas não se identifica e nem utiliza LIBRAS em sua comunicação, não é considerada culturalmente surda perante a comunidade surda. Importante destacar que o decreto publicado em 2005, trouxe duas situações, uma a regulação transitória para o período de ıo anos, a contar da publicação, para possibilitar uma adaptação do país, a lei e a regulação que prevalece a pós esses dez anos. Ou seja, de 2015, pois o que foi estabelecido para o período de transição e adaptação já não se aplica mais.

Sabemos que o surdo tem direito de ser atendido na sua língua a LIBRAS, em qualquer espaço público ou privado de atendimento público. Para o espaço público, todos os espaços de serviços oferecidos e mantido pelo poder público, seja Federal, Estadual, Distrital e Municipal. Para o espaço privado de atendimento público, podemos entender desde lojas comerciais, Bancos etc. Os surdos como proposto por alguns 
autores, são aquelas pessoas que não se identificam e nem utiliza letras em sua comunicação, não se considera culturalmente surdo perante a comunidade surda.

\begin{abstract}
Os surdos, ou Surdos com letra maiúscula, como proposto por alguns autores, são pessoas que não se consideram deficientes, utilizam uma língua de sinais, valorizam sua história, arte e literatura e propõem uma pedagogia própria para a educação das crianças surdas. Os deficientes auditivos seriam as pessoas que não se identificam com a Cultura e a comunidade surda. (BISOL E VALENTINI, 2oII, p. I).
\end{abstract}

\title{
2.3.I Características da Surdez
}

Se por meio da audição a criança que não apresenta nenhuma deficiência auditiva ela aprende naturalmente o modelo de sua língua. Já a criança com surdez, ela aprende a se relacionar a experiência que está vivenciando com a verbalização ou sinais. Ela é capaz de observar em outra pessoa (pais, colegas, etc.), ela busca sua própria experiência para se comunicar com o mundo e as pessoas que convive.

Por meio da audição a criança que não apresenta nenhuma deficiência auditiva aprende naturalmente o modelo de sua língua. Porém, à criança com surdez adquire sua linguagem ao relacionar a experiência que está vivendo com a verbalização e/ou sinais que ela observa em outra pessoa (colegas, pais, professores, etc.), bem como ao relacionar o que está sendo falado pelo outro com suas próprias experiências e também ao comunicar seus pensamentos e experiências de forma oral, escrita ou com sinais (HONORA, FRIZANCO, 2009, p.20).

Conforme o autor, a criança com surdez ela passa a se comunicar com o mundo através de sinais e escritas, observando o que está sendo falado pelo outro. Seja ela de forma oral ou escrita elas vão se comunicando com o mundo, diferente daquela criança que não apresenta nenhuma deficiência ela é capaz de aprender de forma natural.

Os tipos de surdez se diferenciam entre leve onde a pessoa ouve bem os graves, mas sente dificuldade com os agudos. Já os moderados ouvem som graves com menos ruídos, mais se estiver em um ambiente fechados com músicas sentira uma certa dificuldade para ouvir falas. Os surdos não ouvem a fala humana ou qualquer outro tipo de som, sua comunicação é através de sinais, a língua de sinais é tão complexa como qualquer outra, possibilitando a comunidade surda a se comunicar.

As pessoas com surdez enfrentam inúmeros entraves para participar da educação escolar, decorrentes da perda da audição e da forma como se estruturam as propostas educacionais das escolas. Muitos alunos com surdez podem ser prejudicados pela falta de estímulos adequados ao seu potencial 
cognitivo, sócio - afetivo linguístico e político - cultural e ter perdas consideráveis no desenvolvimento da aprendizagem (DAMÁZIO, 2007, p.13).

Considerando as características do autor, e notório expressar que a comunicação no grupo de surdos e bastante perceptível a falta de interação social entre pessoas diferentes. Dependendo dos tipos elevados de surdez é inevitável um desconforto na aceitação no grupo escolar das comunidades. $\mathrm{O}$ acesso a inclusão ainda é bastante precário em relação a aceitação por partes dos colegas de classes. Escolas que não tem estrutura adequada para receber um aluno com deficiência ainda é visto no dia a dia dos alunos. A comunicação total considera as expressões da pessoa com surdez, através de recursos para melhor comunicação, a fim de reforçar suas interações sociais, considerando assim as áreas de aprendizagem e linguística dos alunos.

Segundo Damázio (2007, p.19) a Comunicação Total considera as características da pessoa com surdez utilizando todo e qualquer recurso possível para a comunicação, a fim de potencializar as interações sociais, considerando as áreas cognitivas, linguísticas e afetivas dos alunos.

Os surdos enfrentam uma exclusão desde o século XII, onde eles não podiam nem se casarem porque era proibido, não andavam no meio das pessoas considerada normais, porque não era visto como humanos. Hoje poder utilizar de recursos para sua comunicação com a sociedade, é um grande avanço para o surdo e assim potencializando sua interação social, desenvolvendo suas capacidades intelectuais e emocionais, isto é, linguagem, pensamento, memorias e raciocínio para melhor compreensão.

\subsubsection{Causa da Surdez}

Para o autor alguns fatores podem interferir na aquisição da linguagem, a perda auditiva ela está relacionada a hereditariedade, causada por alguma doença na gravidez. $\mathrm{Na}$ ingestão de medicamentos está o ototóxicos que lesam o nervo auditivo dessa criança. Também são afetados por exposição de sons impactantes.

Para Rinaldi (1997, p.I5) Hereditariedade, viroses maternas (rubéola, sarampo), doenças tóxicas da gestante (sífilis, citomegalovírus, toxoplasmose), ingestão de medicamentos ototóxicos (que lesam o nervo auditivo) durante a gravidez. É adquirida, quando existe uma predisposição genética (otosclerose), quando ocorre meningite, ingestão de remédios ototóxicos, exposição a sons impactantes (explosão) e viroses, por exemplo. 
Sabemos que as perdas auditivas são causadas por alguma doença durante a gravidez, que acabam afetando o bebê, o mais comum dessas perdas e a rubéola, meningite etc. Otites de repetição, é causado por infecção de ouvido, devido ao mau posicionamento do bebê no momento das mamadas, até mesmo por gripes mal curadas. Os surdos geralmente eles se comunicam por língua de sinais (LIBRAS), as perdas auditivas elas são apresentadas por graus, tem o severo e o profundo. A surdez também ela é ocasionada por alguma alteração na estrutura da orelha da criança, e assim ocasionando a sua capacidade de ouvir o som.

A Surdez também é ocasionada por alguma alteração nas estruturas da orelha, ocasionando uma incapacidade em perceber o som. Geralmente o surdo se comunica através da Língua Brasileira de Sinais (LIBRAS) e apresenta uma perda auditiva de grau severo ou profundo (HONORA; FRIZANCO, 2009, p. 25).

É notório que existe um grau de preconceito muito grande de quem tem uma deficiência auditiva, por mais que essa deficiência venha sido causada por alguma alteração das suas estruturas, o surdo sofre uma grande exclusão. Essa exclusão muitas vezes vem da própria pessoa, ele (a) acaba se isolando do ambiente, ele chega a recusar até mesmo um aparelho auditivo porque expõem sua deficiência.

Sabemos que o diagnóstico é eito através de exames e história daquela criança, é preciso avaliar o paciente através de equipamentos especiais, a audiometria é o mais importante para avaliar melhor esse paciente, para poder chegar a um diagnóstico. Quando necessária a ressonância magnética pode ser necessária para uma melhor avaliação.

O diagnóstico da causa da surdez é feito através da história do paciente, exame de ouvido, exames com equipamentos especiais podem ser necessários para avaliar a audição, sendo a audiometria o mais importante. Quando a tontura está associada, investiga - se o labirinto e o sistema nervoso central. A ressonância magnética pode ser necessária quando há suspeita de tumor. (Linden, 1990, 1990p. $76-79$ ).

Sabemos que a comunicação é a primeira das diversas barreiras que o educando vai encontrar quando se deparar com um aluno surdo em sala de aula. O primeiro sentimento para a maioria dos educandos que recebe um aluno com surdez na sala de aula é a insegurança explicita na fala. " Não sei lidar com ele", não sou especialista em surdez etc. A escola precisa de fato está preparado para receber esse aluno surdo, pois a 
falta de domínio de uma língua comum entre o aluno surdo e o professor dificulta, e até mesmo impede a interação com o conhecimento

\subsubsection{A Língua Brasileira de Sinais: Novas Perspectivas para a Educação do Surdo.}

Aprofundando a história da educação de surdos, encontra-se L'Epée, o francês que fundou a primeira escola para surdos em Paris em i76o, que se tornou o modelo que impulsionou a criação de várias escolas também em outros países, segundo Barros (20II). O ano de 1857 pode ser considerado um grande avanço na educação de surdos com métodos de comunicação e várias tentativas subsequentes, principalmente por meio de signos, segundo Nerly e Ricardo (2005).

No Brasil, o professor surdo francês Hernest Huet fundou a primeira Escola de Surdos a convite de D. Pedro II, o Imperial Instituto dos Surdos-Mudos, com base em um método combinado. Outro fato marcante, agora negativo, foi o Congresso de Milão, realizado em 1880, no qual estiveram presentes apenas 3 professores surdos que concordaram que a Língua de Sinais seria retirada da educação de surdos, mantendo a Língua, segundo os autores Perlin e Strobel ( 2006). Com esse veredicto, podemos considerar um atraso significativo na inclusão do aluno surdo no processo ensinoaprendizagem, uma vez que ele foi proibido de praticar sua língua e foi excluído de sua própria cultura por cerca de cem anos.

A LIBRAS, língua brasileira de sinais, a libras por ela ser uma língua, ela tem todo uma característica, todos os seus aspectos que o transformam em língua. A LIBRAS expressa ideias sutis, complexas e abstrata, possui gramatica própria e algumas variações de sinais por região.

Segundo Fernandes (2003, p. 39), as línguas de sinais são sistemas abstratos de regras gramaticais, naturais das comunidades de indivíduos surdos que as utilizam.

Sabemos que a LIBRAS não é universal, cada país tem a sua própria língua de sinais. A percepção visual $\mathrm{e}$ as expressões faciais e corporais são um dos fatores fundamentais da língua brasileira de sinais. Assim como o português é a primeira língua para o indivíduo ouvinte nascido no Brasil, a língua Brasileira de sinais também é a primeira língua do surdo, ou sua língua materna. É por meio da LIBRAS que o surdo se comunica, tem acesso à cultura, conhecimento e a interação social. 
Existem duas formas de língua: a língua natural, ou primeira língua, aprendida desde o nascimento e outra que funciona como segunda língua. No caso da pessoa com surdez no Brasil, a primeira língua é a Libras, e a segunda, o português escrito. Segundo Goldfeld (2002, p. 39).

Temos que olhar o surdo como um brasileiro que não ouve, o surdo enfrenta uma barreira, a comunicação, o surdo ele é uma pessoa completa e independente. A inclusão não precisa ser só na sala de aula, ela precisa ser incluída na sua casa também, muitas vezes aquela criança não brinca com outra criança ouvinte porque sua mãe não deixa, o surdo é capaz de tudo, ele é inteligente. Contudo que a escola oferece para o aluno surdo, o intérprete, as salas de recursos, os serviços oferecidos, ele ainda precisa se sentir inserido nesse contexto.

O professor itinerante, aquele que auxilia o professor regente a incluir a criança com necessidades educacionais:

\begin{abstract}
Mesmo na escola que conta com um intérprete, com uma sala de recursos, com serviço e apoio de professor de educação especial ou professor itinerante, é de fundamental importância que o aluno sinta que seu professor está se esforçando para se aproximar dele, tentando encontrar maneiras de interagir com ele. O professor também pode intermediar a aceitação do aluno pelos outros alunos, para que ele se sinta parte da classe. Eustáquio (2013) cita Reily (2008, p. 125).
\end{abstract}

Mesmo que esse aluno possa contar com todos esses recursos, ele ainda enfrenta as barreiras na sua vida. Ele ainda encontra um professor que não está preparado para lidar com suas necessidades educacional. Por outro lado, encontramos escolas que está devidamente prepara para esse aluno (a) com necessidades.

Língua Brasileira de sinais é uma forma de linguagem natural, que foi instituída para promover a inclusão social dos deficientes auditivos, os benefícios que a língua de sinais trouxe para a comunidade surda, foi a interação social que garantiu o acesso a convivência com outras pessoas, tornando-os importante e útil para alguma atividade em sociedade.

\footnotetext{
Mais do que a utilização de uma língua, os alunos com surdez precisam de ambientes educacionais estimuladores, que desafiem o pensamento, explorem suas capacidades, em todos os sentidos. Se somente o uso de uma língua bastasse para aprender, as pessoas ouvintes não teriam problemas de aproveitamento escolar, já que entram na escola com uma língua oral desenvolvida. Damásio (2007, p. I4 apud EUSTÁQUIO, 2013).
}

Em uma sociedade em plena transformação, onde os direitos e deveres são para uma pequena parcela da sociedade. Observa-se que a comunidade surda tem um desafio 
grande ao se inserir na sociedade, o que deveria estimular seu acesso a sociedade é o mesmo que não possibilita essa interação. A escola é sem dúvidas uma modalidade que inseri essas pessoas, necessitando de ajustes principalmente nas esferas governamentais, escolas de ensino fundamental que possibilite esse acesso ao convívio social com outras crianças.

\section{RESULTADOS E DISCUSSÕES}

\section{I Inclusão de estudantes surdos: Identificação das metodologias que contribuem para o} desenvolvimento integral do Surdo

A qualidade auditiva é um diferencial significativo no processo de aprendizagem na assimilação de informações e de forma sequencial, conforme Vygotsky conceitua:

Nessa interação, os próprios surdos produzem significados que permitem compreender em que são diferentes. Ao contrário, essa diferença só pode ser confirmada e vivida como tal, pressupondo igualdade e reciprocidade. Daí a importância de preservar o direito dos surdos ao desenvolvimento, incluindo-os em experiências de acordo com a heterogeneidade dos processos humanos. (WYGOTSKI 1993, p. 33).

As crianças surdas enfrentam outro desafio no sistema educacional, pois as escolas não oferecem aos alunos surdos as mesmas condições pedagógicas de leitura e escrita que os alunos ouvintes, porque eles não falam a mesma língua. Segundo Araújo (2015), a língua de sinais é utilizada indevidamente no contexto do ensino da alfabetização, sem levar em consideração o real direito das crianças surdas de usar sua própria língua.

$\mathrm{O}$ autor afirma ainda que a linguagem visual-espacial é realizada como um método adicional e não leva em conta devidamente o seu conjunto linguístico. Por conta dessa situação, a exclusão dos surdos se agrava ainda mais e eles podem ser tratados como desqualificados para entender o português em sua organização.

\subsection{A formação continuada dos docentes que trabalham com criança surda}

Incluir a criança é uma questão delicada para a escola, pois é necessária uma melhor organização da estrutura escolar, todo o aparato pedagógico e pessoal qualificado 
para responder a esta procura, para cumprir a função de integração social da seguinte forma declara Orzech:

\begin{abstract}
A política de integração deve ser implementada sob a forma de programas de formação e acompanhamento contínuo que orientem o ensino tendo em vista a redução gradual da exclusão escolar, com o objetivo de beneficiar não só os alunos com necessidades especiais, mas também a educação como um todo. (NOGUEIRA, 2002, p. 77).
\end{abstract}

\title{
4. METODOLOGIA
}

Foi realizado um método, com base na revisão de literatura nacional e internacional, empregando os bancos de dados PUBMED, MEDLINE e SCIELO abordando os escritores relacionados ao tema da inclusão de aluno surdo em escola regular, foi feito uma pesquisa bibliográfica. Por meio da pesquisa bibliográfica do qual através das informações adquiridas no decorrer do trabalho, foi possível compreender as informações, assim como orientações.

A pesquisa bibliográfica é o levantamento ou revisão de obras publicadas sobre a teoria que irá direcionar o trabalho científico o que necessita uma dedicação, estudo e análise pelo pesquisador que irá executar o trabalho científico e tem como objetivo reunir e analisar textos publicados, para apoiar o trabalho científico. Para Gil (2002, p. 44), a pesquisa bibliográfica é desenvolvida com base em material já elaborado, constituído principalmente de livros e artigos científicos.

Segundo ( KOCHE, 2003, p.I2I) "toda pesquisa de certa magnitude tem que passar por uma fase preparatória de planejamento". Planejar constitui buscar prováveis alternativas para serem realizadas, buscando a flexibilidade do conhecimento - o que é a fundamental especialidade do planejamento de uma pesquisa, procurando explicar seu processo de solução.

Segundo Reis (2010) o método de pesquisa consiste em uma série de etapas e processos a serem seguidos, os quais são realizados de forma ordenada na investigação, e representa o processo desde a geração do problema até o progresso gradual. Até que a resposta seja obtida.

Segundo Fonseca (2002) a pesquisa é realizada por meio de uma busca de estudos teóricos que já foram analisados e publicados, seja por meios eletrônicos ou escritos, tais como: artigos científicos, livros, entre outros. 
Para Lakatos e Marconi (2007), a indução representa um processo psicológico, por meio do compartilhamento de dados privados, após a devida verificação, para inferir a verdade geral ou geral, e não incluído na parte da fiscalização. Portanto, o objetivo da argumentação do método indutivo é tirar conclusões cujo conteúdo é muito mais amplo do que baseado em premissas.

Segundo Gerhardt e Silveira (2009), a pesquisa bibliografica enfoca aspectos da compreensão e explicação da dinâmica das relações sociais. Segundo o autor, esse modelo inclui significado, motivação, aspirações, valores, etc., incluindo objetificar fenômenos, graduar a descrição, compreensão, interpretação e comportamento preciso da relação entre o global e o local.

\section{CONSIDERAÇÕES FINAIS}

Finalizando o trabalho, podemos considerar que para que haja inclusão do aluno surdo é necessário que as pessoas envolvidas no processo educacional façam um esforço, no sentido de se livrarem de modelos pré-determinados de homem, de entenderem a importância de que o aluno realize suas próprias elaborações, que compartilhe suas dúvidas, suas descobertas e seu poder de decisão. Conclui-se que a inclusão de surdos no ensino regular significa mais do que apenas criar vagas e proporcionar recursos materiais, é necessário que a escola e a sociedade sejam inclusivas, assegurando igualdade de oportunidades a todos os alunos e contando com professores capacitados e compromissados com a educação de todos.

A Educação Inclusiva que envolve o processo de alfabetização de crianças surdas tem como objetivo garantir as mesmas oportunidades e chance a todos os estudantes. Por meio deste estudo objetivou-se compreender a importância da educação inclusiva das crianças surdas no processo de alfabetização. Portanto, levando-se em consideração os aspectos que foram analisados podemos compreender que a melhor forma para que haja inclusão do aluno surdo é necessário que haja a parceria e conscientização entre governo, comunidade e família, será possível amenizar os problemas sociais e educacional, construindo uma sociedade mais justa e com menos problemas sociais volta ao progresso, só assim poderemos manter a solução desta problemática. 


\section{REFERÊNCIAS}

ARAÚJO, L. C. N. Alfabetização e Letramento. Rio de janeiro: UVA-Ilumno, (produção técnica e material didático). 2015.

ARRUDA, Marco Antônio; ALMEIDA Mauro de. Cartilha da inclusão escolar: Inclusão Baseada em Evidências Científicas. Rio Preto: ABDA, 2004.

BRASIL. Decreto no 5.626, de 22 de dezembro de 2005. Regulamenta a Lei no Io.436, de 24 de abril de 2002, que dispõe sobre a Língua Brasileira de Sinais - Libras, e o art. i8 da Lei no 10.098, de 19 de dezembro de 2000. Diário Oficial da União, 23.dez.2005.

BRASIL. Lei de Diretrizes e Bases da Educação Nacional, LDB. 9394/1996. BRASIL.

BISOL, C.A. \& VALENTINI, C.B. Surdez e Deficiência Auditiva - qual a diferença? Objeto de Aprendizagem Incluir - UCS/FAPERGS, 20Ir. Disponível em: acesso: $17 / 01 / 22$

BRASIL. Ministério da Educação e do desporto. Referencial Curricular Nacional de Educação Infantil: formação pessoal e social. Brasília: MEC/SEF, vls. I e 2, 1998.

CARVALHO Rosita Edler. Educação Inclusiva: com os pingos nos is. 3. ed. Porto Alegre: Mediação, 2005.

CAMPOS, M. L. I. L. Educação Inclusiva para Surdos e as Políticas Vigentes. In: LACERDA, C. B. F.; SANTOS, L. F. (Orgs.). Tenho um aluno surdo, e agora? Introdução à LIBRAS e educação de surdos. São Carlos: EDUFSCar, 2014.

DECLARAÇÃO DE SALAMANCA: Sobre princípios, políticas e práticas na área das necessidades educativas especiais. Salamanca - Espanha, 1994.

DAMÁZIO, M. F.M. Deficiência Auditiva. Brasília, DF: MEC/SEESP, 2007. 
DAMÁZIO, M. F.M. Deficiência Auditiva. Brasília, DF: MEC/SEESP, 2007.

EUSTÁQUIO, Rosilane N. P. O papel do instrutor de Libras no ensino regular. 2013. Disponível em: , acesso em: I6 de Maio de 202I.

EUSTÁQUIO, Rosilane N. P. O papel do instrutor de Libras no ensino regular. 2013

FARFUS, D. Organização pedagógica dos espaços educativos. Disciplina: Organização Pedagógica Espaços Educativos do curso de Pedagogia EaD da FACINTER. Curitiba, 2009 .

FREIRE, P. Pedagogia da autonomia: saberes necessários à prática educativa. 13. ed. São Paulo: Paz e Terra, 2005.

FERNANDES, Eulália. Linguagem e surdez. Porto Alegre: Artmed, 2003.

FONSECA, J. J. S. da. Metodologia da pesquisa científica. Fortaleza: UEC, 2002.

GerhardT, T. E.; SIlveirA, D. T. (Org.). Métodos de Pesquisa. Porto Alegre: Editora da UFRGS, 2009.

GIL, A. C. Como Elaborar Projetos de Pesquisa. 6ae ed. São Paulo: Atlas, 2002.

GOLDFELD, Márcia. A criança surda: linguagem e cognição numa perspectiva sociointeracionista. São Paulo: Plexus, 2002.

HONORA, Márcia; FRIZANCO, Mary Lopes Esteves. Esclarecendo as deficiências. São Paulo: Cirando Cultural, 2009. 
LAKATOS, E. M.; MARCONI, M. de A. Fundamentos de metodologia científica. 6. ed. 5. reimp. São Paulo: Atlas, 2007.

LIDEN, A et AL. Deficientes auditivos severos e profundos: um estudo retrospectivo e uma análise prospectivas. Rev. Bras. Otorrinolaringol. Rio de Janeiro, v.56, n.2, p.76 79, abril/junho. 1990.

MANTOAN, Maria Teresa Egler. Inclusão Escolar: o que é? por quê? como fazer? São Paulo: Moderna, 2003.

NOGUEIRA, M. L.L. Políticas educacionais e a formação de professores para a educação inclusiva no Brasil. Revista integração. MEC. Secretaria de Educação Especial, V.14, n. 24, 2002. p.77.

PARO, Vitor Henrique. As funções da escola, a estrutura didática e a qualidade do ensino. In: PARO, V. Gestão escolar, democracia e qualidade do ensino. São Paulo: Ática. 2007.

PERLIN, G.; STROBEL, K. L. Fundamentos da Educação de Surdos. (Desenvolvimento de material didático ou instrucional - Educação de surdos). 2006.

REIS, F. L. dos. Como elaborar uma dissertação de mestrado. Lisboa: Pactor, 2010.

SASSAKI, R. K. Inclusão: construindo uma sociedade para todos. Rio de Janeiro, WVA, 1997 .

SASSAKI, Romeo. Kazumi. Inclusão, o paradigma da próxima década. Mensagem, Brasília, v. 34, n. 83, p. 29, 1998.

Sanches, I., \& Teodoro, A. (2007). Procurando indicadores de educação inclusiva: As práticas dos professores de apoio educativo. Revista Portuguesa de Educação, 20(2), I05-I49. VYGOTSKY, L. Pensamento e Linguagem. São Paulo: Martins Fontes, 1993, p. 33 
KOCHE, José Carlos. Fundamentos de Metodologia Científica. Petrópolis: Vozes, 2003, p. I2I. 